\title{
La revista en una etapa diferente
}

\author{
The journal in a different stage
}

Dr. Julio Yarmuch

Nuestra revista ha debido migrar, por razones de fuerza mayor, desde la plataforma editorial europea Elsevier a Open Journal System (OJS), plataforma de origen universitario y gubernamental estadounidense y canadiense.

La primera es una empresa de larga trayectoria, que ha ido a lo largo del tiempo mejorando sus procesos en forma sostenida y con la que luego de dos años habíamos logrado un trabajo armónico y fluido, lo que permitía obtener un producto final de calidad en el que había una importante presencia y visibilidad nacional e internacional; entre otros nos permitía nuestra presencia en Scopus, empresa propiedad de Elsevier. Aun cuando el costo de la revista así procesada, dado lo caro de la empresa editorial era muy alto e íntegramente financiado por la Sociedad de Cirujanos, nuestros Directorios habían asumido lo que ello implicaba. Como ya ha sido comentado antes, la transnacional europea decidió hace algunos meses en forma unilateral, aparentemente por razones de conveniencia, desvincularse de la mayoría de las revistas chilenas y muchas de América Latina - entre ellas la Revista Chilena de Pediatría, que está en Pubmed e ISI-.

Dado lo anterior hemos buscado el alero editorial de OJS, plataforma multiuniversitaria sin fines comerciales, que aboga por el libre acceso a la información médica. Si bien intuíamos que el cambio iba a presentar dificultades, estas han sido mayores de las esperadas, pues la funcionalidad y el acceso al sistema son diferentes y más complejas, al menos en las etapas iniciales.

Ello ha implicado además, la creación de una nueva página web, propia de la publicación, en la que de a poco hemos estado insertando los números anteriores y que contiene a la revista en su versión digital. De acuerdo a lo programado desde hace varios años, en un futuro próximo este formato reemplazará prácticamente por completo a la revista escrita tradicional.

La publicación ha continuado apareciendo en los períodos en que corresponde, con material que estaba en espera en el anterior sistema y todos los artículos que habían sido aceptados serán publicados en los primeros números de este año.

Sin embargo, los autores que comienzan el proceso editorial enviando sus artículos, y también nuestros amables pares revisores, deberán tener paciencia para lograr incorporarse a este nuevo ciclo. Para ello les solicitamos que se interioricen con la nueva página web en www.revistacirugia. $\mathrm{cl}$, además les ofrecemos toda la ayuda que requieran, la que puede ser solicitada directamente a jyarmuched@gmail.com o a manuelfigueroa.gi@ gmail.com (Julio Yarmuch y Manuel Figueroa) o también a nuestro asesor informático y experto en publicaciones científicas Italo Costa (italo.costar@ gmail.com

Les invitamos a continuar publicando sus artículos en nuestra revista.
Editor Jefe.

Correspondencia a: jyarmuched@gmail.com 